\title{
THE EFFECT OF INTRAGASTRIC BALLOON ON METABOLIC PROFILE IN OBESE PATIENTS IN COMPARISON TO MINI GASTRIC BYPASS
}

\author{
By
}

\section{Ahmed Samir Abo-Halima, Khalid Zakaria El-Karmouty, Zainab Ahmed Ali El-Din, Mohammed Mahfouz Mohammed*, Samy Mahmoud and Sherif Sadek Shabana}
Department of Internal Medicine, Gastroenterology \& Hepatology and *General Surgery, Faculty of Medicine, Ain Shams University, Egypt

Corresponding Author: Ahmed Samir Abo-Halima,

E-mail: dr.abohalima@hotmail.com

\begin{abstract}
Background: Throughout the last decade, the treatment of obesity has slowly undergone a paradigm shift. The advent of endoscopic balloon therapy has had a profound impact on long-term weight management. Endoscopic balloons have been used to treat obese patients seeking weight loss.

Objective: To evaluate the safety and effectiveness of intra gastric balloon compared to gastric bypass surgery as the standard of care.

Patients and methods: This study included 30 obese patients fit for endoscopic treatment by intragastric balloon (BMI equal or more than 35) and 15 diabetic patients fit for Mini gastric bypass BMI > $35 \mathrm{~kg} / \mathrm{m} 2$. Their ages ranged 18 - 45 years. All balloons were done in private center (Masrscope Endoscopy Center) in Cairo. Mini gastric bypass operations were done in Aldemerdash Hospital during period from March 2016 till September 2016.

Results: Age was $18-45$ years (60\% females). Initial body mass index (BMI) was 35-43 kg/m2. Three early removals were encountered due to intolerance. BMI reduction ranged 15-40\% at balloon removal after 6 months and 25-50\% after mini gastric bypass. Metabolic profile improved in all patients. Eighty percent of patients were satisfied with the balloon and $50 \%$ with mini gastric bypass.

Conclusion: After 6 months following surgery, the small gastric bypass resulted in a considerable weight loss. There were few problems, excellent safety, and substantial efficacy when treating obese individuals with balloon implantation. Even before a scheduled bariatric surgical treatment, endoscopic intra gastric balloon implantation is an effective and safe technique of reducing extra body mass in obese individuals.
\end{abstract}

Keywords: Bariatric endoscopy, Intragastric balloons, Metabolic syndrome, Obesity treatment, Weight loss.

\section{INTRODUCTION}

The prevalence of obesity continues to increase worldwide. Because obesity is associated with a number of health-related problems as well as a shortened life span, treating obesity is an important clinical concern. Although various treatments are currently available, many are not efficacious in the long term. Therefore, additional medical treatment options for morbidly obese individuals must be explored (Bužga et al., 2014).

The treatment of obese patients is a demanding and long-term undertaking, in 
which there are no shortcuts or quick fixes (Franz et al., 2011). In patients with morbid obesity $(\mathrm{BMI}=40 \quad \mathrm{~kg} / \mathrm{m} 2)$, conservative treatment appears ineffective (Avenell et al., 2010). Obese subjects who do not qualify for, or do not give consent to, bariatric surgical procedures constitute a therapeutic problem. An endoscopic method for the treatment of obesity, intragastric balloon, can be an option for this group of patients (KonopkoZubrzycka et al., 2012).

The intragastric balloon has been shown to be a safe and effective procedure for temporary weight reduction, with low mortality and morbidity (Genco et al., 2011). Intragastric balloons have played an essential role in the preoperative treatment of morbidly obese patients who are scheduled to undergo bariatric or other elective surgery by minimizing mortality and morbidity risks (Genco et al., 2013). Excess fat mass is often seen in conjunction with a constellation of other cardiovascular risk factors such as hypertension, dyslipidemia and hyperglycemia, so-called metabolic syndrome (Grundy et al., 2011). In recent years the prevalence of metabolic syndrome has increased directly with the epidemic of obesity (Park et al., 2011).

The aim of this study was to determine the value of intragastric balloon on the metabolic profile in obese patients in comparison to those after mini gastric bypass.

\section{PATIENTS AND METHODS}

This was a retrospective analysis of collected data from patients who underwent intra- gastric balloon insertion and mini gastric bypass with a multidisciplinary follow-up program.

This study included 30 obese patients fit for endoscopic treatment by intragastric balloon (BMI equal or more than 35) and 15 diabetic patients fit for Mini gastric bypass BMI > 35kg/m2. Their ages ranged 18 - 45 years. All balloons were done in private centers in Cairo. Mini gastric bypass operations were done in Aldemerdash Hospital during period from March 2016 till September 2016.

This study was performed after obtaining informed consent from all participating subjects enrolled in the study.

\section{Patients were divided into three equal groups:}

1. Group I: Obese non diabetic patients underwent intragastric balloon.

2. Group II: Obese diabetic patients underwent intragastric balloon.

3. Group III: Obese diabetic patients underwent Mini-Gastric bypass surgery.

\section{Exclusion criteria:}

1. Patients who removed the balloon before 6 months.

2. Patients receiving lipid lowering agents (statins or fibrates).

3. Patients on long term steatosis inducing drugs (corticosteroids, tamoxifen, amiodarone and valproic acid).

4. I.V. drug users.

5. Other viral or alcoholic liver diseases.

6. Pregnant and/or nursing females. 
7. Patients refusing to be entitled in the study.

8. Acute gastritis, gastric and duodenal ulcers.

9. Respiratory disorders (sleep apnea and/or tachypnea after little physical activity).

10. Unfit patients for general anesthesia or other contra-indications of laparoscopy for the surgical group.

\section{All participants were subjected to the following:}

BMI, complete blood picture, AST, ALT, serum total proteins, serum albumin, total and direct bilirubin, and GGT levels, BUN, creatinine, sodium, potassium, INR, FBS, 2HPP, total cholesterol, triglycerides, high-density lipoprotein (HDL), low-density lipoprotein (LDL), and very low-density lipoprotein (VLDL), HBA1c, HCV Ab.

An approval of the study was obtained from Ain Shams University academic and ethical committee. Every patient signed an informed written consent for acceptance of the operation.

Balloons were inserted in the outpatient environment using conventional methods, while under sedation with midazolam (5-10 mg iv).

To begin, all groups had diagnostic upper endoscopy to rule out any patients with contraindications. Under endoscopic view, the empty balloon was then inserted into the patient's stomach. The balloon was filled with $500 \mathrm{~mL}$ of saline and methylene blue up to a maximum capacity of $700 \mathrm{~mL}$. The patient was kept in the recovery room for two hours after the procedure for observation. Patients were given antiemetics such metoclopramide for a few days after the operation. The balloon was inserted into the stomach with the help of a guidewire within the catheter.

Using a video gastroscope, the balloon was placed in a fasting patient after sedation and local pharyngeal anesthetics with 4 percent lignocaine solution.

The balloon is filled with 0.9 percent $\mathrm{NaCl}$ solution mixed with methylene blue up to a maximum total capacity of $700 \mathrm{ml}$ after it has been released into the stomach for precise placement. To avoid a high pressure in the valve, the balloon was carefully inflated on a continual basis. Within the stomach, the inflated balloon should move freely. The syringe was then used to create a negative pressure in the filling catheter, which closed the valve and regulates its tightness. When more than $5 \mathrm{ml}$ of fluid aspirated via the catheter after inflating the balloon, the valve is not tight.

Before disconnecting the catheter and withdrawing the endoscope, the balloon's position was checked, particularly against the exit and to ensure that there was no impaction within the stomach. During the postoperative phase, patients were required to follow the following instructions: After the procedure, $5 \mathrm{mg}$ of hyoscine butylbromide every 6 hours for 3 days was given. After the procedure, a proton pump inhibitor at a dose of 40 $\mathrm{mg}$ /day for two days, then $20 \mathrm{mg} /$ day for 15 days was given. Metoclopramide hydrochloride 60-40 mg/day if vomiting occurred. Follow-up visits were in the first, second, and fourth weeks following the operation, followed by monthly visits. Control abdomen ultrasound was in the 
3rd month after the procedure to assess the balloon volume.

In the postoperative period, the patients were obliged to observe the following dietary treatment regime:

- A liquid or semi-liquid diet for the first 3 days following the surgery, with 3-4 meals per day and at least 1 hour between meals, avoiding spice, caffeine, sweets, and cold meals. Drinking of $1000-1500 \mathrm{~mL}$ of water was each day.

- Starting on the fourth day following the surgery, gradually transition was to a solid food. If vomiting occurred, a semi-liquid diet was switched for three meals in a row. Three to four meals each day, no drinking during meals, sparkling mineral water and coffee, sweets, olive oil, and other highcalorie foods were all recommended.

- Six months after implantation, the balloon was removed. The patients were instructed to go on a liquid diet for three days prior to the operation. A panendoscope was used to extract the balloon from the stomachs of fasting and sedated individuals. The balloon's content was suctioned after it was perforated with a steel guidewire and terminated with a needle and catheter. The balloon's wall was shattered using forceps in the area opposite the valve and carefully removed from the digestive tract after it was totally empty.

All patients were operated on laparoscopically, with general anesthesia, in the Trendlenburg position, with pneumo-peritoneum, followed by the creation of a longitudinal gastric pouch starting from the incisura on a $38 \mathrm{fr}$ Bougie towards the angle of His, followed by a linear stapler end to side gastrojejunostomy at 2 metres from the D-J flexure, methylene blue test, and closed system drainage.

Six months after the procedure, all groups were invited for a follow-up including a clinical examination, BMI and collection of blood samples for lipid profile, liver enzymes and glycosylated hemoglobin.

\section{Statistical Methods:}

The collected data were coded, tabulated, and statistically analyzed using IBM SPSS statistics (Statistical Package for the Social Sciences) software version 22.0, IBM Corp., Chicago, USA. Descriptive statistics were done for quantitative data as minimum \& maximum of the range as well as mean \pm SD (standard deviation), while it was done for qualitative data as number and percentage. Inferential analyses were done for quantitative variables using paired t-test in cases of two dependent groups with normally distributed data and ANOVA test with post hoc Tukey test for more than two independent groups with normally distributed data. In qualitative data, inferential analyses for independent variables were done using Chi square test for differences between proportions. While correlations were done using Pearson correlation for numerical normally distributed data. $\mathrm{P}$ value $<0.05$ was considered significant. 


\section{RESULTS}

This study had been conducted on 45 patients with BMI more than $35 \mathrm{~kg} / \mathrm{m} 2$. Ages of patients ranged were from 18 to 45 years with mean $30.4 \pm 10.2$. Non diabetic patients were 5 males $(33.3 \%)$ and 10 females $(66.6 \%)$. patients with diabetes mellitus were 13 males (43\%) and $17(57 \%)$ females. There was no significant difference between study groups regarding age and gender (Table 1).

Table (1): Comparison between study groups regarding age and gender

\begin{tabular}{|c|c|c|c|c|c|}
\hline \multicolumn{2}{|c|}{$\begin{array}{ll}\text { Variables } & \text { Groups } \\
\end{array}$} & $\begin{array}{l}\text { Group I } \\
(\mathrm{N}=15)\end{array}$ & $\begin{array}{c}\text { Group II } \\
(\mathrm{N}=15)\end{array}$ & $\begin{array}{c}\text { Group III } \\
(\mathrm{N}=15)\end{array}$ & $\mathbf{P}$ \\
\hline \multirow{2}{*}{$\begin{array}{c}\text { Age } \\
\text { (years) }\end{array}$} & Mean \pm SD & $30.4 \pm 8.0$ & $31.9 \pm 10.2$ & $32.5 \pm 5.4$ & \multirow{2}{*}{0.765} \\
\hline & Range & $18.0-45.0$ & $18.0-45.0$ & $18.0-40.0$ & \\
\hline \multirow{2}{*}{$\begin{array}{c}\text { Sex } \\
(n, \%)\end{array}$} & Male & $5(33.3 \%)$ & $7(46.7 \%)$ & $6(40.0 \%)$ & \multirow{2}{*}{0.757} \\
\hline & Female & $10(66.7 \%)$ & $8(53.3 \%)$ & $9(60.0 \%)$ & \\
\hline
\end{tabular}

The compared body mass index (BMI) after intervention between the three groups showed a significantly decrease in all groups with p-value $<0.001$. BMI reduction was significantly highest in group-III with no significant difference between group I and group II (Table 2).

Table (2): Comparison between study groups regarding BMI (kg/m2)

\begin{tabular}{|c|c|c|c|c|c|}
\hline \multicolumn{2}{|c|}{$\begin{array}{ll}\text { BMI } & \text { Groups } \\
\end{array}$} & Group-I & Group-II & Group-III & $\wedge \mathbf{P}$ \\
\hline \multirow{2}{*}{ Before } & Mean \pm SD & $37.1 \pm 3.0$ & $38.0 \pm 2.4$ & $36.7 \pm 2.2$ & \multirow{2}{*}{0.338} \\
\hline & Range & $35.0-43.0$ & $35.0-43.0$ & $35.0-42.0$ & \\
\hline \multirow{3}{*}{ After } & Mean \pm SD & $26.9 \pm 1.7$ & $27.4 \pm 1.6$ & $24.2 \pm 0.8$ & \multirow{3}{*}{$<0.001$} \\
\hline & Range & $23.0-29.5$ & $25.0-29.5$ & $23.0-26.0$ & \\
\hline & Tukey's test & $\begin{array}{c}\mathrm{I} / \mathrm{II} \\
0.675\end{array}$ & $\begin{array}{c}\text { II/III } \\
<0.001\end{array}$ & $\begin{array}{c}\text { I/III } \\
<0.001\end{array}$ & \\
\hline \multirow{3}{*}{${ }^{\&}$ Change } & Mean \pm SD & $-10.2 \pm 2.0$ & $-10.6 \pm 1.5$ & $-12.5 \pm 2.1$ & \multirow{3}{*}{0.003} \\
\hline & Range & $-13.5--8.0$ & $-13.5--8.0$ & $-17.0--10.0$ & \\
\hline & Tukey's test & $\begin{array}{c}\mathrm{I} / \mathrm{II} \\
0.801 \\
\end{array}$ & $\begin{array}{l}\text { II/III } \\
0.004 \\
\end{array}$ & $\begin{array}{c}\text { I/III } \\
0.021 \\
\end{array}$ & \\
\hline & $\mathbf{P}$ & $<0.001$ & $<0.001$ & $<0.001$ & \\
\hline
\end{tabular}

$\wedge$ ANOVA test with post hoc Tukey test (between groups), \#paired t-test (between times), \&Change=Afterbefore (negative values indicate reduction) 
The compared HbA1c between the three groups after intervention revealed significant difference between all groups with p-value $<0.001$. HbA1c was significantly changed in group III, followed by group II then group I (Table 3).

Table (3): Comparison between study groups regarding HbA1c

\begin{tabular}{|c|c|c|c|c|c|}
\hline \multicolumn{2}{|c|}{ HbA1c Groups } & Group-I & Group-II & Group-III & $\wedge \mathbf{P}$ \\
\hline \multirow{3}{*}{ Before } & Mean \pm SD & $5.0 \pm 0.3$ & $8.6 \pm 1.6$ & $8.4 \pm 1.6$ & \multirow{3}{*}{$<0.001$} \\
\hline & Range & $4.5-5.5$ & $6.5-12.0$ & $6.9-12.3$ & \\
\hline & Tukey's test & $\begin{array}{c}\text { I/II } \\
<0.001\end{array}$ & $\begin{array}{l}\text { II/III } \\
0.894\end{array}$ & $\begin{array}{c}\text { I/III } \\
<0.001\end{array}$ & \\
\hline \multirow{3}{*}{ After } & Mean \pm SD & $4.8 \pm 0.3$ & $7.7 \pm 1.4$ & $6.6 \pm 0.4$ & \multirow{3}{*}{$<0.001$} \\
\hline & Range & $4.4-5.3$ & $5.4-10.5$ & $6.0-7.4$ & \\
\hline & Tukey's test & $\begin{array}{c}\text { I/II } \\
<0.001 \\
\end{array}$ & $\begin{array}{l}\text { II/III } \\
0.004\end{array}$ & $\begin{array}{c}\mathrm{I} / \mathrm{III} \\
<0.001\end{array}$ & \\
\hline \multirow{3}{*}{${ }^{\&}$ Change } & Mean \pm SD & $-0.2 \pm 0.1$ & $-0.9 \pm 0.4$ & $-1.8 \pm 1.4$ & \multirow{3}{*}{$<0.001$} \\
\hline & Range & $-0.3--0.1$ & $-1.5--0.4$ & $-5.2--0.4$ & \\
\hline & Tukey's test & $\begin{array}{c}\text { I/II } \\
\mathbf{0 . 0 4 5}\end{array}$ & $\begin{array}{l}\text { II/III } \\
0.017\end{array}$ & $\begin{array}{c}\text { I/III } \\
<0.001\end{array}$ & \\
\hline \multicolumn{2}{|c|}{ \#P } & $<0.001$ & $<0.001$ & $<0.001$ & \\
\hline
\end{tabular}

$\wedge$ ANOVA test with post hoc Tukey test (between groups), \#paired t-test (between times), \&Change=Afterbefore (negative values indicate reduction)

There was no significant correlation between change in BMI and age. There were significant positive correlations between change in BMI and change in blood glucose and lipid profile (Table 4).

Table (4): Correlation between change in BMI and age \& change in blood glucose and lipid profile

\begin{tabular}{|c|c|c|c|c|}
\hline \multirow{2}{*}{ Parameters } & Groups & \multirow{2}{*}{ Group I } & Group II & Group III \\
\hline \multirow{2}{*}{ Age } & $\mathbf{r}$ & 0.096 & -0.478 & 0.259 \\
\cline { 2 - 5 } & $\mathbf{P}$ & 0.733 & 0.071 & 0.350 \\
\hline \multirow{2}{*}{ Change in FBG } & $\mathbf{r}$ & 0.969 & 0.746 & 0.953 \\
\cline { 2 - 5 } & $\mathbf{P}$ & $<\mathbf{0 . 0 0 1}$ & $<\mathbf{0 . 0 0 1}$ & $<\mathbf{0 . 0 0 1}$ \\
\hline \multirow{2}{*}{ Change in PPBG } & $\mathbf{r}$ & 0.901 & 0.719 & 0.931 \\
\cline { 2 - 5 } & $\mathbf{P}$ & $<\mathbf{0 . 0 0 1}$ & $\mathbf{0 . 0 0 3}$ & $<\mathbf{0 . 0 0 1}$ \\
\hline \multirow{2}{*}{ Change in HbA1c } & $\mathbf{r}$ & 0.902 & 0.666 & 0.940 \\
\cline { 2 - 5 } & $\mathbf{P}$ & $<\mathbf{0 . 0 0 1}$ & $\mathbf{0 . 0 0 7}$ & $<\mathbf{0 . 0 0 1}$ \\
\hline \multirow{2}{*}{ Change in Cholesterol } & $\mathbf{r}$ & 0.962 & 0.672 & 0.966 \\
\cline { 2 - 5 } & $\mathbf{P}$ & $<\mathbf{0 . 0 0 1}$ & $\mathbf{0 . 0 0 6}$ & $<\mathbf{0 . 0 0 1}$ \\
\hline \multirow{2}{*}{ Change in Triglycerides } & $\mathbf{r}$ & 0.932 & 0.824 & 0.750 \\
\cline { 2 - 5 } & $\mathbf{P}$ & $\mathbf{< 0 . 0 0 1}$ & $<\mathbf{0 . 0 0 1}$ & $<\mathbf{0 . 0 0 1}$ \\
\hline
\end{tabular}




\section{DISCUSSION}

In the present study, the placement and removal of the balloon were performed on an outpatient basis with the patient under conscious sedation compared to mini gastric bypass surgery under general anesthesia. At the end of the 6-months treatment period, $100 \%$ of the obese patients (45/45) showed significant weight loss taking into consideration that three patients had early balloon removal and two patients with minigastric bypass were not committed to follow up.

The current study included 30 obese patients fit for endoscopic treatment by intragastric balloon (BMI more than or equal 35) and 15 diabetic patients for Mini gastric bypass BMI > 35. This study showed that BMI significantly decreased in all groups. BMI after intervention was significantly changed in group III with no difference between group I and group II.

BMI reduction was significantly highest in group III with no difference between group I and group II and this is agree with Noria and Grantcharov (2013) and Carvalho et al. (2016) those found that BMI reduction after gastric balloon by $15-40 \%$ of basal weight and by 20 $50 \%$ after minigastric bypass.

This study showed that HbA1c significantly decreased in all groups. HbA1c was significantly changed in group III, followed by group-II. This agree with Mui et al. (2010) whose studied on 119 obese patients assessed the effects of the Orbera intragastric balloon on obesity-associated diseases and quality of life. They found that six months after placement of the intragastric balloon, the rate of metabolic syndrome in the patients decreased from $42.9 \%$ to $15.1 \%$.
Cholesterol, triglycerides, fasting glucose, and blood pressure also improved after balloon treatment. In patients with diabetes mellitus, the HbA1c level was decreased $(7.4 \%$ to $5.8 \%)$. Another nonblinded study conducted by Mingrone et al. (2012), comparing gastric bypass and obese diabetic with medical therapy, found $75 \%$ in RYGB and $10 \%$ in medical therapy had diabetes remission (fasting plasma glucose [FPG] $<100 \mathrm{mg} / \mathrm{dl}$ and $\mathrm{HbA} 1 \mathrm{c}<6.5 \%$ without medication).

Current study showed that cholesterol and triglycerides significantly decreased in all groups. Cholesterol and triglycerides reduction were significantly highest in group-III with no difference between group-I and group-II. This is totally agree with the meta-analysis by Buchwald et al. (2012) who showed that hyperlipidemia, hypercholesterolemia and hypertriglyceridemia were significantly improved across all procedures. The percentage of patients whose conditions improved was typically $70 \%$ or higher. There was a significant decrease in total cholesterol (mean change $0.86 \mathrm{mmol} / \mathrm{L}$ ) and triglycerides (mean change $0.9 \mathrm{mmol} / \mathrm{L}$ ).

This study showed there were significant positive correlations between change in BMI and change in blood glucose and lipid profile and this agree with Rubino (2010), Buchwald et al. (2012) and Noria \& Grantcharov (2013). These meta-analysis studies showed improvement of FBS, PPBS and lipid profile of patients after BMI reduction either after gastric balloon or gastric bypass and more beneficial with mixed procedures (malabsorptive and restrictive) (Rubino, 2010). 


\section{CONCLUSION}

After six months of intervention showed that all groups their BMI decreased and metabolic profile significantly improved but it is more in group with minigastric bypass, but as complication is more with surgery. So, intragastric balloon is more preferable by the patients.

\section{REFERENCES}

1. Avenell A, Brown TJ, McGee MA, Campbell MK, Grant AM, Broom J, Jung RT and Smith WC. (2010): What are the long-term benefits of weight reducing diets in adults? A systematic review of randomized controlled trials. J Hum Nutr Diet., 17(4):317335

2. Buchwald $\mathbf{H}$, Avidor $\mathbf{Y}$ and Braunwald $\mathbf{E}$. (2012): Bariatric surgery: a systematic review and meta-analysis. JAMA, 292:1724-37.

3. Bužga M, Evžen M, Pavel K, Tomáš K, Vladislava $Z$, Pavel $Z$ and Svagera $Z$. (2014): Effects of the intragastric balloon medsil ${ }^{\circledR}$ on weight loss, fat tissue, lipid metabolism, and hormones involved in energy balance. Obes Surg., 24(6): 909-915.

4. Carvalho GL, Diego LL, Prashanth R and Fernandes F. (2016): Intragastric Balloon for Overweight Patients. JSLS, 20(1): 107-112.

5. Franz MJ, Vanwormer JJ, Crain AL, Caplan W, Bowman JD and Pronk NP. (2011): Weight-loss outcomes: a systematic review and meta-analysis of weight-loss clinical trials with a minimum 1-year followup. J Am Diet Assoc., 107: 1755-67.

6. Genco A, Cipriano M, Bacci V, Cuzzolaro M, Materia A, Raparelli L, Docimo C, Lorenzo $M$ and Basso N. (2011): BioEnterics intragastric balloon (BIB): a short-term, double-blind, randomised, controlled, crossover study on weight reduction in morbidly obese patients. Int J Obes., 30:129133.

7. Genco A, López-Nava G, Wahlen C, Maselli R, Cipriano M and Sanchez MM.
(2013): Intragastric balloon or diet alone? A retrospective evaluation. Obes Surg., 18(8):989-992.

8. Grundy SM, Cleeman JI, Daniels SR, Savage PJ, Smith SC and John A. (2011): Diagnosis and management of the metabolic syndrome: an American heart association/national heart, lung, and blood institute scientific statement. Curr Opin Cardiol., 21(1):1-6.

9. Konopko-Zubrzycka M, Baniukiewicz A, Wróblewski E and Kowalska I, Zarzycki W, Górska M Dabrowski A. (2012): The effect of intragastric balloon on plasma ghrelin, leptin, and adiponectin levels in patients with morbid obesity. J Clin Endocrinol Metab., 94(5):1644-1649.

10. Mingrone G, Panunzi S, De Gaetano A and Busetto L. (2012): Bariatric surgery versus conventional medical therapy for type 2 diabetes. N Engl J Med., 366: 1577-85.

11. Mui WL, Ng EK, Tsung BY, Lam CH and Yung MY. (2010): Impact on obesity-related illnesses and quality of life following intragastric balloon. Obes Surg., 20:11281132.

12. Noria $F$ and Grantcharov $T$ (2013): Biological effects of bariatric surgery on obesity-related comorbiditiesCan J Surg., 56(1): 47-57.

13. Park YW, Zhu S, Palaniappan L, Heshka S, Carnethon MR and Heymsfield SB. (2011): The metabolic syndrome: prevalence and associated risk factor findings in the US population from the third national health and nutrition examination survey. Arch Intern Med., 163(4):427-436.

14. Rubino F. (2010): Bariatric surgery: effects on glucose homeostasis. Curr Opin Clin Nutr Metab Care, 9: 497-507. 


\section{تأثثير بالون المعدة علي التمثيل الغذائي في مرضي السمنة مقارنة بتحويل مسار المعدة المصنر الفئري}

أحمد سمير أبو حليمة، خالد زكريا القرموطي، زينب أحمد علي الدين، محمد محفوظ محمد*، سامي محمود، شريف صادق شبانة

قسم الباطنة العامة والجهاز الهضمي والكبد، والجراحة العامة*، كلية الطب، جامعة عين شمس، مصر

E-mail: dr.abohalima@hotmail.com

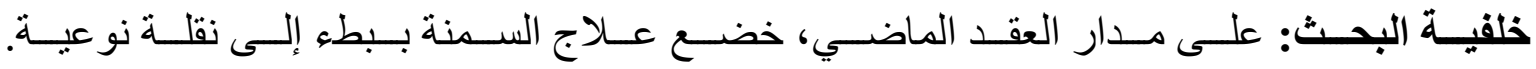

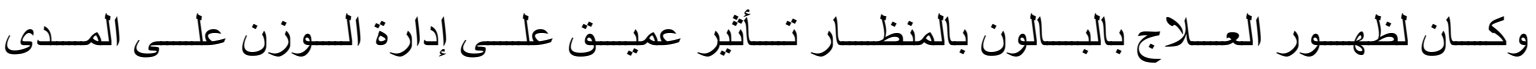

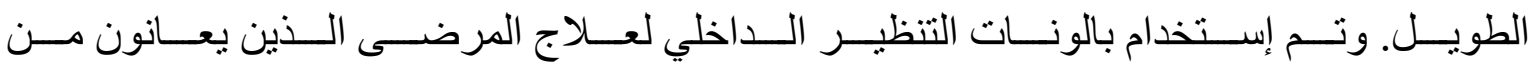
السمنة الدفرطة و الذين يسعون لفقدان الوزن.



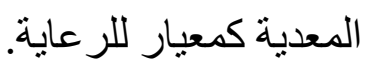

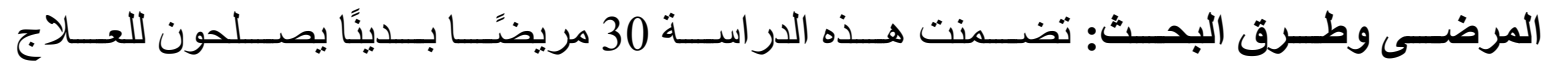

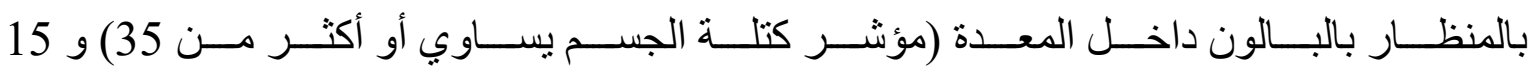

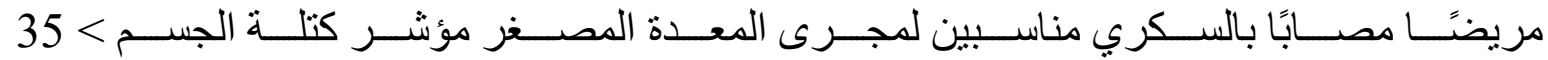

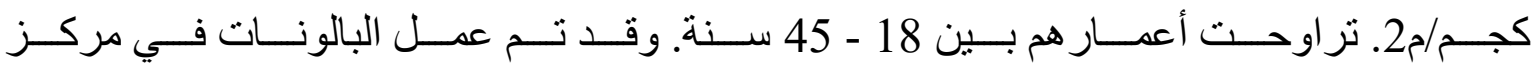



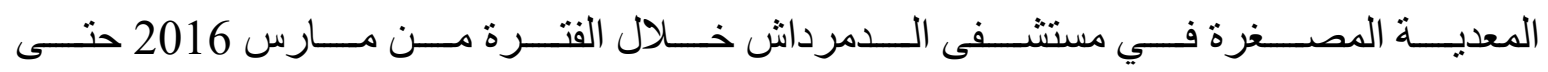
سبتمبر 2016.

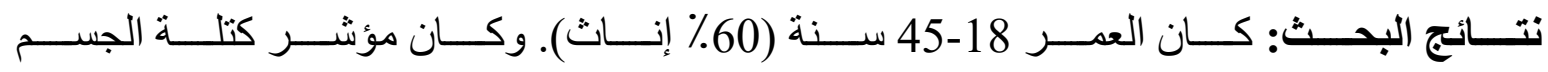

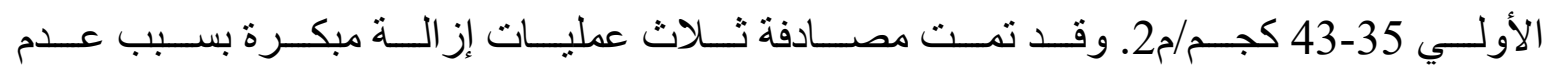

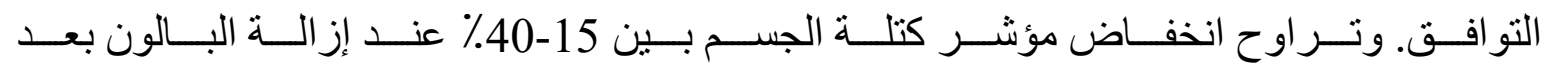

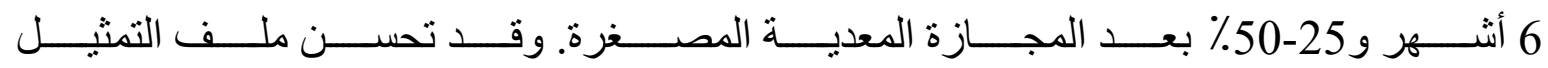

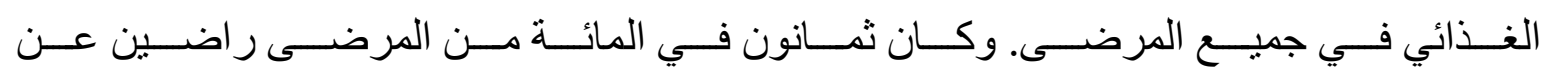
البالون، 50 في المائة عن المجازة المعدية المصغرة. 


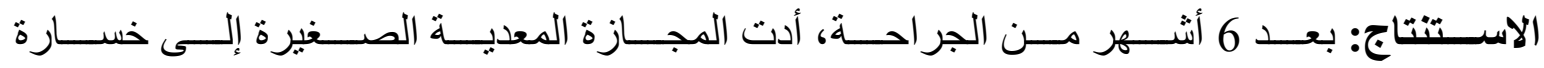

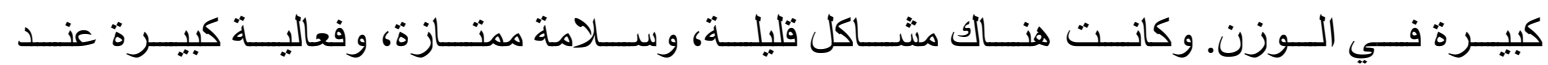

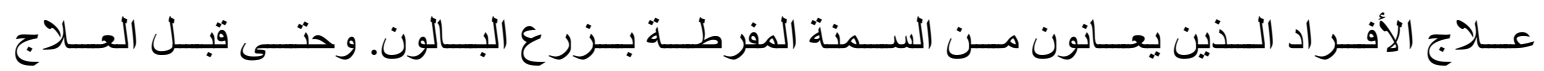

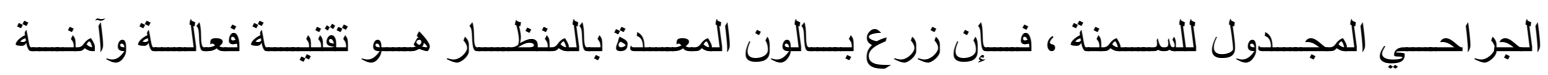
لتقليل كتلة الجسم الزائدة لدى الأشخاص الذين يعانون من السمنة الدفرطة.

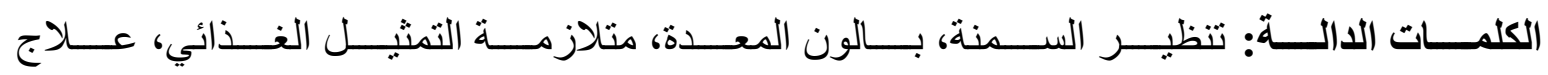

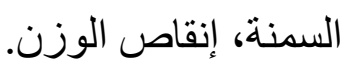

